\title{
Repellent and insecticidal effect of the invasive plant Melilotus officinalis (L.) Pall. on Tenebrio molitor L.
}

\author{
Elena Gulik $^{1,{ }^{*}}$, Svetlana Mikhailova ${ }^{1,2}$, Andrey Babenko ${ }^{1}$, Qasim H.A. Aljboori ${ }^{3}$ \\ ${ }^{1}$ National Research Tomsk State University, av. Lenine, 36, Tomsk, 634050, Russia \\ ${ }^{2}$ All-Russian Plant Quarantine Center (VNIIKR), Tomsk Branch, av. Frunze, 109A, Tomsk, 634021, \\ Russia \\ ${ }^{3}$ University Of Al-Qadisiyah, Iraq
}

\begin{abstract}
The repellent and insecticidal effect of invasive alien plant Melilotus officinalis L. on Tenebrio molitor L. in a laboratory experiment were studied. The repellent activity of the dry crushed aboveground part of M. officinalis, added to oatmeal and spring wheat, was studied in relation to the larvae of $T$. molitor. The best repellent effect of $M$. officinalis was observed in relation to $T$. molitor larvae when added to oatmeal. The insecticidal activity of an aqueous extract of the aboveground part of $M$. officinalis was studied on larvae and imago of $T$. molitor. A pronounced insecticidal effect of $M$. offcicinalis on the imago $T$. molitor was established in the absence of an effect on the larvae.
\end{abstract}

\section{Introduction}

In the context of agricultural pest control, botanical pesticides are best suited for use in the production of organic food in industrialized countries, but can play a much larger role in the production and post-harvest protection of food in developing countries [1]. Studies on the usefulness and effectiveness of invasive alien plants as insecticides for plants are few [2, 3].

Melilotus officinalis (L.) Pall., known as yellow sweetclover, a plant belonging to the Fabaceae family, is widely used in medicine and agriculture. At the same time, yellow clover is a weed and invasive plant in Siberia [4].

There is a single information about the repellent activity of $M$. officinalis. Antifeedant property and average toxicity $\left(\mathrm{LC}_{50}=5.6 \mathrm{mcg} / \mathrm{ml}\right)$ of methanol extract of sweet clover for Spodoptera litoralis larvae were demonstrated [5]. The aboveground part of $M$. officinalis is poisonous and contains various chemicals, secondary plant metabolites and biological active substances: coumarines and their derivatives, flavonoides, melilotin, essential oil, saponins, derivatives of purine, phenol-carbon acids, phenol triterpene compounds, nitrogen compounds, amino-acids, tannins fatty-like substances, macro- and micro-elements [6].

* Corresponding author: gulik59@,inbox.ru 


\section{Material and methods}

The repellent activity of $M$. officinalis in relation to the larvae of Tenebrio molitor was determined in an experiment on the free choice of food. During experiments, $50 \mathrm{~g}$ of oatmeal or $50 \mathrm{~g}$ of wheat grain (control) and $50 \mathrm{~g}$ of oatmeal or $50 \mathrm{~g}$ of spring wheat grain with $2 \%$ dry crushed aboveground part of yellow clover were placed in cotton bags loosely tied (experiment). The bags were placed in a circle in a plastic basin with a volume of 20 liters. Middle-aged (37-60 mg) larvae were released into the center of the pelvis at the rate of 10 larvae per bag. The basin was covered with a cloth from above and removed into the darkness. After 7 days, the larvae were counted inside each pouch. The experiment was carried out in 3-4 repetitions. The index of repellent activity was calculated according to Wang et al. [7].

For an experiment to determine the insecticidal activity of plant mixtures on the mortality of imago and larvae T. molitor an aqueous extract of M. officinalis was used.

The oatmeal was soaked in distilled water (control) and an aqueous extract of $M$. officinalis (experiment) for 30 seconds. Then the soaked oatmeal was dried to an absolutely dry state in a drying box. The prepared oatmeal $(10 \mathrm{~g})$ was placed in 6 plastic containers with a volume of $250 \mathrm{ml}$ ( 3 control and 3 experimental), carrots as a source of moisture and 10 imago or 10 larvae of $T$. molitor were launched into each container.

Statistical processing was carried out using the Statistica 10.0 software package and the Microsoft Excel program. The significance of the differences was assessed using the nonparametric Mann-Whitney test $(\mathrm{p}<0.05)$.

\section{Results}

The repellent effect of yellow clover was studied on larvae of T. molitor.

In the variant with oatmeal as a food substrate with the addition of $M$. officinalis, a repellent effect was observed against insects larvae (repellent activity index $=50 \%$ ) with a significance level of $81 \%$, which indicates an average repellent effect of yellow clover on larvae of T. molitor.

The use of spring wheat as a food substrate with the addition of yellow sweetclover had a weak repellent effect against larvae of $T$. molitor (repellent activity index $=10 \%$ ).

Thus, the greater repellent activity of the yellow clover against to the larvae was noted when using food more preferable for T. molitor as a food substrate.

Thus, the degree of repellent action of $M$. officinalis depends on the food substrate to which dry plant material was added. Thus, the addition of $M$. officinalis to a more preferred food substrate (oatmeal) had a more pronounced repellent effect on larvae of T. molitor compared to less preferred food (spring wheat).

The insecticidal activity of $M$. officinalis was studied on imago and larvae of T. molitor, which were kept on oatmeal moistened with an aqueous extract of yellow clover.

In the experiment with the imago, the death of insects in the experimental group began from 29 days, while in the control group - from 49 days (Fig.). A significant difference in mortality between the experiment and the control was noted from 45 days to 89 days (from $30 \%$ to $47 \%$ ). By the end of the experiment (day 89 ), the mortality rate in the control was $10 \%$, while in the experimental group it was $57 \%$.

Thus, the content of imago T. molitor on oatmeal soaked with extracts from $M$. officinalis led to a significant difference in mortality between the control and experimental groups ( $47 \%$ at the end of the experiment).

Thus, M. officinalis has an insecticidal effect on the imago of T. molitor. 


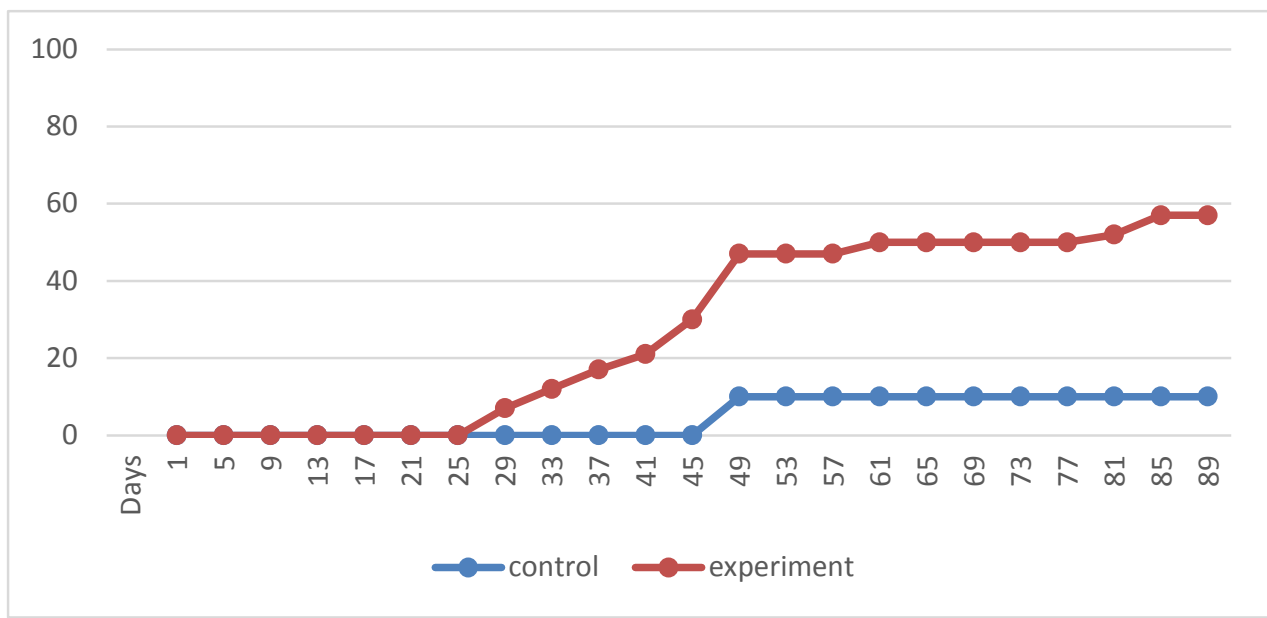

Fig. Dynamics of Tenebrio molitor imago mortality (\%) when kept on oatmeal moistened with an aqueous extract from the Melilotus officinalis

When studying the insecticidal activity of $M$. officinalis against to the larvae of $T$. molitor and their subsequent development, data were obtained on the 95th day of the experiment (Table).

Table. Influence of larval conditions on oatmeal moistened with extract Melilotus officinalis on the viability of Tenebrio molitor

\begin{tabular}{|l|l|l|l|l|l|l|c|}
\hline Groups & $\begin{array}{l}\text { Surviving } \\
\text { larvae } \\
(95 \text { days })\end{array}$ & $\begin{array}{l}\text { Death } \\
\text { at } \\
\text { larval } \\
\text { stage }\end{array}$ & Pupation & $\begin{array}{l}\text { Surviving } \\
\text { pupae } \\
\text { (95 days) }\end{array}$ & $\begin{array}{l}\text { Death at } \\
\text { pupal } \\
\text { stage }\end{array}$ & $\begin{array}{l}\text { Born } \\
\text { imago }\end{array}$ & $\begin{array}{l}\text { Death at } \\
\text { imago } \\
\text { stage }\end{array}$ \\
\hline Control & $83 \%$ & $13 \%$ & $4 \%$ & - & - & $4 \%$ & - \\
\hline Experiment & $37 \%$ & $10 \%$ & $53 \%$ & $10 \%$ & - & $43 \%$ & $3 \%$ \\
\hline
\end{tabular}

As can be seen from the table, yellow clover helps to accelerate the transition of larvae to the subsequent stages of development.

Thus, Melilotus officinalis has insecticidal activity on imago of Tenebrio molitor. The content of $T$. molitor larvae on a substrate with yellow clover extract has practically no effect on the mortality of the insects at all subsequent stages of development.

It is possible that the repellent and insecticidal effect of M. officinalis on T. molitor is due to the presence of biologically active substances, in particular essential oils, coumarin and its derivatives in the composition of M. officinalis.

Thus, the degree of repellent action of $M$. officinalis depends on the food substrate to which dry plant material was added. The degree of insecticidal activity of $M$. officinalis in relation to T. molitor depends on the stage of development of the insect.

\section{References}

1. M.J. Joshi, C.B. Solanki, A.G. Inamdar, V.V. Birari, R. V Prithiv, Latest trends in zoology and entomology sciences, 10, 53-75 (2020)

2. Ž. Laznik, T. Bohinc, S. Trdan, Acta Agric. Slov., 111 (2), 501-509 (2018) 
3. T. Bohinc, A. Horvat, M. Ocvirk, I.J. Košir, K. Rutnik, S. Trdan, Appl. Sci. 10 (2), 7828 (2020). doi:10.3390/app10217828

4. Black book of the flora of Siberia (Novosibirsk, 2016)

5. R. Pavela, T. Chermenskaya, Plant Protection Sci., (4), 145-150 (2004)

6. O.O. Boyko, V.V. Brygadyrenko, Biosystems Diversity, 27(3), 227-232 (2019)

7. X.Wang, Q. Hao, Y. Chen, S. Jiang, Q. Yang, Q. Li, Journal of Insect Science, 15(1), $1-7(2015)$ 